Research Article

\title{
Bow and Stern Control Surface's Effectiveness and Influence on Supercavity
}

\author{
Ping Wei $\mathbb{D}^{1},{ }^{1}$ Wenrong Yan, ${ }^{1,2}$ Shoufa Wang, ${ }^{1}$ and Xin Yu ${ }^{1}$ \\ ${ }^{1}$ College of Weaponry Engineering, Naval University of Engineering, Wuhan 430033, China \\ ${ }^{2} X i^{\prime} a n$ Modern Chemistry Research Institute, Xi'an 710065, China \\ Correspondence should be addressed to Ping Wei; pingwei501@126.com
}

Received 16 September 2021; Revised 1 November 2021; Accepted 15 November 2021; Published 3 December 2021

Academic Editor: Min Xia

Copyright (C) 2021 Ping Wei et al. This is an open access article distributed under the Creative Commons Attribution License, which permits unrestricted use, distribution, and reproduction in any medium, provided the original work is properly cited.

\begin{abstract}
The numerical model of supercavitating flow field was established based on multiphase model, cavitation model, and turbulence model. The model was employed to simulate the supercavitation flow for the supercavitating vehicle with two types of control surfaces: bow rudder and stern rudder. The influence of both control surfaces on the supercavity shape and rudder effectiveness is compared under the different rudder angles $\left(0-12^{\circ}\right)$, and the effectiveness and the influences on supercavities of bow rudder and stern rudder were explored according to the numerical research results. From the research results, the following conclusions can be drawn: (1) the bow rudders have stable rudder effectiveness and available rudder angle, and the bow rudders also have significant influence on supercavities' shape. (2) By contrast with the bow rudder, stern rudders' effectiveness is difficult to predict accurately, and the phenomenon of stalling will occur when stern rudders' rudder angle exceeds $6^{\circ}$; however, there is almost no influence of stern rudders on supercavities. (3) The bow and stern rudders joint control mode must take the influence on supercavities' shape and the accuracy of control force's forecasting into account at the same time. The research is helpful to the optimizing of superhigh-speed vehicles and the design of control modes.
\end{abstract}

\section{Introduction}

With the aid of a powerful propulsion device, the ultrahighspeed underwater vehicle can achieve a superhigh speed of more than $200 \mathrm{kn}$ in underwater [1], because it relies on the unique hydrodynamic layout mode to achieve a substantial reduction in the drag of the vehicle by wrapping most of the body in the supercavity. However, due to the existence of supercavitation, the hydrodynamic characteristics and the response characteristics of the control system displayed for the ultrahigh-speed vehicle are very different from those of the conventional underwater vehicle. Therefore, the optimization of the hydrodynamic layout and the navigation control mode are the research focus and difficulty and are also current research hotspots $[2,3]$. The supercavitating vehicle mainly adopts the stern rudder control mode, the bow rudder control mode, and the joint control mode of the bow and stern control mode, and the precise prediction of rudder effect and supercavity shape is the key to the research of supercavitation navigation control technology $[3,4]$.
The supercavitation vehicle obtains greater control power by increasing the wetted area of the rudder blade, which can change the rudder effect characteristics and the cavitation shape because of the interaction between the rudder blade and the cavitation. Ignoring the deformation of supercavity and representing the rudder effect with the wetted area of the theoretical rudder blade, Wang et al. [5] used a wedge-shaped stern rudder as the control surface and studied the dynamic modeling and control problems. Li et al. [6] proposed a hydrodynamic layout mode using bow rudder control and studied the strong manoeuver control technology of supercavitating vehicles through ballistic simulation, but this study did not consider the effect of the hydroplaning of the body because of the main body cavitation deformation caused by the bow rudder. Dzieiski and Kurdila [7] proposed a hydrodynamic prediction method for wedge-shaped rudder blades coupled with cavitation and studied the control technology of supercavitating vehicle with the proposed method. Kuklinski [8] used experimental methods to study the formation and development of cavitation in disc 
cavitator, conical cavitator, star-shaped cavitator, and coneshaped cavitator with bow rudder and also carried quantitative analysis of the influence of multiple supercavitation morphology.

According to publicly published documents, the control force of ultrahigh-speed vehicle mainly comes from the hydrodynamic force of the bow rudder or the stern rudder. The navigation control is mainly based on theoretical cavitation to estimate the rudder effect according to the wetted area. Accurate prediction of the control force of supercavitating vehicle is very important for the optimization of hydrodynamic layout and navigation control research. To the best of our knowledge, there is no report on the study of the interaction between supercavitation and rudder. Both the bow rudder and the stern rudder cause the deformation of the main body cavitation, and the change of the cavitation shape also affects the rudder efficiency. In this paper, numerical simulation is used to study the rudder effect of the bow and stern rudder and the corresponding influence on the supercavitation shape of the main body. The prediction method of the rudder effect and the cavitation shape of the supercavitation vehicle is proposed to demonstrate the bow and stern rudder, and the pros and cons of the control mode are also discussed. The research results of this paper can provide references for the optimization of supercavitation hydrodynamic layout and the research of navigation control technology.

\section{Numerical Model and Empirical Formula}

For the study of supercavitation flow, the model test of lowspeed variation has many limitations, and the process of high-speed cavitation test is difficult to control, and the results are difficult to observe. A large number of verification tests show that the numerical method simulates supercavitation flow with good performance [9, 10]. Based on the numerical methods and meshing strategies introduced in the literature, numerical models were established for the ultrahigh-speed aircraft with bow rudder and stern rudder control modes, respectively, and the rudder effect of the control surface and its influence on the supercavitation shape were also studied.

2.1. Description of the Problem. The control force of the bow and tail rudders is derived from the fluid power of the rudder blades for a supercavitating vehicle, and the puncture of the rudder blades will inevitably affect the cavitation shape nearby and afterwards. The cavitation deformation near the rudder blade will change the wetted area of the rudder blade, which in turn changes the rudder effect.

According to the position of the control surface, the supercavitating vehicle mainly adopts three control modes: the bow rudder mode, the stern rudder mode, and the joint control mode of the bow and stern rudder. The stern rudder mode relies on the rudder blade to pierce the cavitation to generate control force, which is difficult to accurately predict the rudder effect; the bow rudder mode uses the rudder blades installed on the cavitator to control navigation, and the rudder effect is stable, and the working distance is large, which has a greater impact on the main body cavitation; the joint control mode of the bow and stern rudder is a new type of hydrodynamic layout mode, with the rudder piece of a smaller size, which combines the characteristics of the bow rudder mode and the stern rudder mode.

In this paper, numerical models were established for supercavitating vehicle with different hydrodynamic layout modes, and the rudder efficiency of the bow rudder and stern rudder and their influence on the supercavitation shape were studied, respectively. The bow and stern rudders adopt the classic "cross" layout pattern. The tail rudder is installed at the end of the cylindrical section of the vehicle, and the bow rudder is arranged on the conical cavitator. The layout of the bow and stern rudder is shown in Figure 1.

Both the bow rudder and the stern rudder use $24^{\circ}$ wedgeshaped rudder blades. The rudder blades and the dimensions of the stern rudder model refer to a supercavitating underwater vehicle that adopts the stern rudder control mode. The diameter of the disc cavitator is $24 \mathrm{~mm}$, the chord length is $20.18 \mathrm{~mm}$, and the spread length is $44 \mathrm{~mm}$. According to the principle of approximate equal resistance, the cavitation and tail rudder dimensions of the bow and rudder control mode are designed, which uses a $90^{\circ}$ cone-shaped cavitation with a bottom diameter of $84 \mathrm{~mm}$, a bow rudder chord length of $13.6 \mathrm{~mm}$, and a bow rudder maximum elongation of $26.1 \mathrm{~mm}$, and rudder area is $301 \mathrm{~mm}^{2}$. Considering that the actual rudder effect of the stern rudder is related to the high speed of cavitation puncture, the effective area of the rudder blade is small, and the action distance of the rudder force of the stern rudder is longer, so the area of the bow rudder is only $20 \%$ of the area of the stern rudder.

2.2. Governing Equation. The governing equations involved in the numerical simulation of supercavitation flow include gas-liquid two-phase continuity equations, momentum equations, and turbulence equations. According to literature [11], the research content of this paper belongs to the homogeneous flow problem, and the mixture multiphase flow model can be used. The cavitation problem can be considered by the mass transfer between the phases described by the Schnerr and Sauer model. The turbulence simulation adopts realizable $k$-e turbulence model, which is robust and suitable for solving complex flow problems. The near-wall processing method in turbulence simulation can use scaled wall functions.

2.3. Model Processing and Meshing. This paper mainly studies the hydrodynamic characteristics of rudder blades under supercavitation conditions when rudder blades exist. In order to simplify the calculation process, the bow rudder model establishes the geometric model of the conical cavitation and the wedge-shaped rudder blades, without considering the rear body of the aircraft. The stern rudder model needs to consider the puncture of the stern rudder to the cavitation; therefore, a complete geometric model of the supercavitating vehicle is established, including the disc cavitator, the nose cone section, the cylindrical section, the stern rudder, and the tail nozzle. On the basis of the bow rudder and tail rudder models, the rudder blades are 


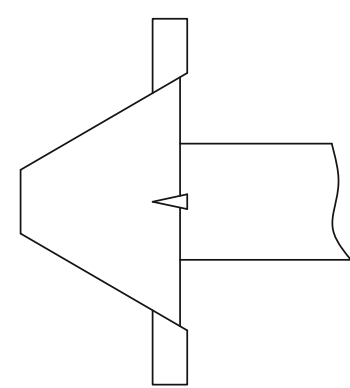

(a) Installation of bow rudders

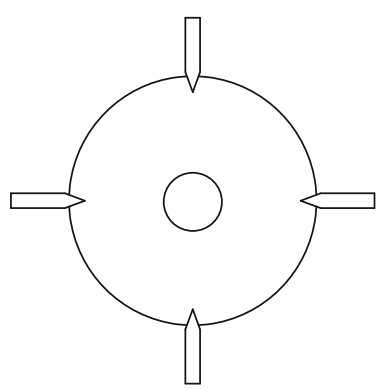

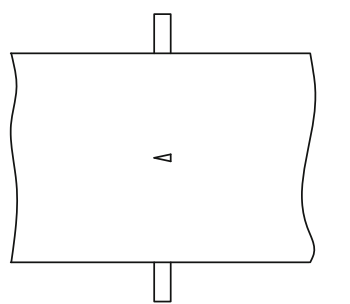

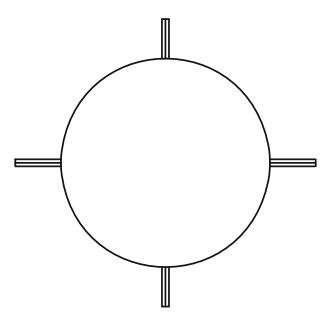

(b) Installation of stern rudders

FIgURE 1: Local modes of the bow rudder and stern rudder: (a) the bow rudder; (b) the stern rudder.

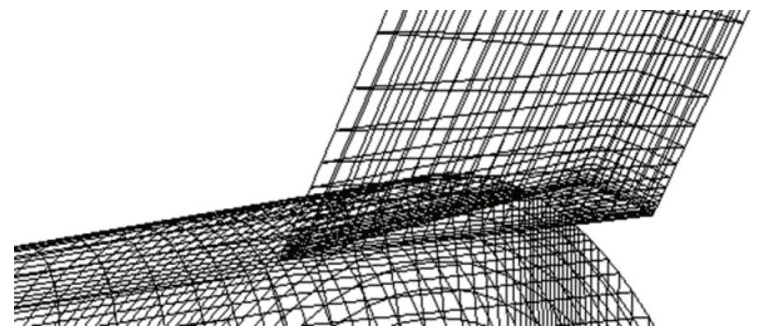

(a) Grid of bow rudders

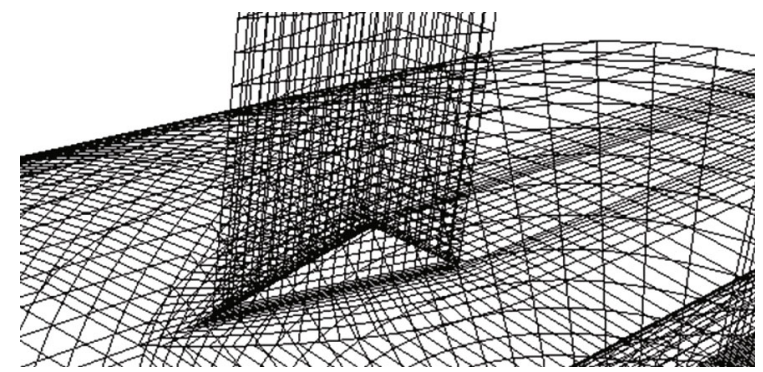

(b) Grids of stern rudders

Figure 2: Grid distribution near the rudder blades. (a) The bow rudder model; (b) the stern rudder model.

removed, and the model without appendage is established. By comparing the numerical simulation results with or without rudder blades, the influences of the bow rudder and stern rudder on the cavitation shape are studied, respectively.

For the numerical simulation of supercavitating flow involving the capture of phase transition and two-phase interface, a reasonable choice of the calculation domain scale during modeling can reduce the influence of boundary conditions on the calculation results. The diameter of the calculation domain is 35 times the maximum cross-sectional diameter of the theoretical cavity. The distance between the entrance of the calculation domain and the cavitator is 1 times the full length of the theoretical cavitation, and the distance between the outlet of the calculation domain and the cavitator is 2 times the full length of the theoretical cavitation.

According to the established geometric models of the bow and stern rudders, the GAMBIT software is used to divide the structured grid, and a boundary layer to the near wall is added, and the near wall grids are optimized to accurately simulate turbulence based on the turbulence model's requirements for $y+$. The wake area around the rudder blades and behind the rudder blades is divided into sufficiently fine grids to accurately capture cavitation bubbles. The grid independence test is carried to ensure that the numerical simulation results of the cavitation shape and fluid dynamics without the influence of the grid distribution.

According to the above-mentioned model simplification method and grid division principle, the geometric model of the rudder angle of $0^{\circ} \sim 12^{\circ}$ is established, and the grid is divided at $1^{\circ}$ intervals, for the bow rudder and the stern rudder, respectively. The number of grid elements of the bow rudder model is 1.8 million, while the number of grid units in the stern rudder model is 2.2 million. The unattached models for reference with the bow rudder and stern rudder models are relatively simple, with a grid size of 0.9 million and 1.2 million, respectively. Taking the $0^{\circ}$ working condition as an example, the grid distribution of the bow rudder and stern rudder models near the rudder blades is shown in Figures 2(a) and 2(b), respectively.

2.4. Boundary Condition Setting. The calculation domain uses a velocity inlet with free stream velocity of $100 \mathrm{~m} / \mathrm{s}$. The calculation domain uses a pressure outlet with an absolute pressure of $118540 \mathrm{~Pa}$. The natural cavitation model is used to simulate the generation and development of supercavitation with a cavitation pressure of $3540 \mathrm{~Pa}$. The calculation domain is surrounded by sliding walls, ignoring shear to weaken the influence of the wall on the flow field.

\section{Numerical Simulation Study of Bow and Stern Rudder Models}

According to the established bow rudder and stern rudder models, numerical simulation studies were carried out, respectively, and the hydrodynamic characteristics of the rudder blades and the influence of the rudder blades on the cavitation shape were obtained.

3.1. Layout of the Bow Rudder Mode. According to the numerical results of the $0 \sim 12^{\circ}$ rudder angle, the 


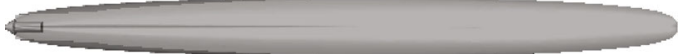

(a) Supercavity produced by cavitator with bow rudders (wholly)

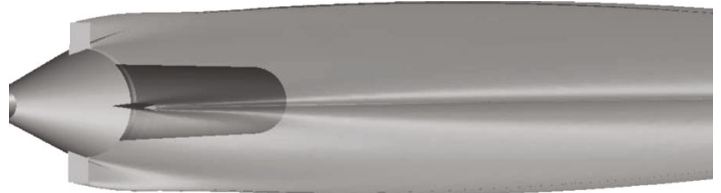

(b) Supercavity produced by cavitator with bow rudders (partly)

FIGURE 3: Supercavitating shape when the rudder angle of the bow and rudder is $0^{\circ}$. (a) The overall cavitation morphology; (b) the initial cavitation morphology.

hydrodynamic characteristics of the bow rudder are counted, and the rudder effect characteristics of the bow rudder are obtained. Compared with the model excluding the bow rudder, the influence of the bow rudder on the major supercavity shape is obtained, by analyzing the deformation of the supercavity.

\subsubsection{The Influence of Bow Rudder on Supercavitation} Morphology. The bow rudder changes the inherent shape of the rotating body of the cavitator, resulting in a change in the shape of the supercavitation. Literature [12] pointed out that during the motion of supercavitating vehicle, the body would inevitably appear water skiing and be subjected to greater "hydroplaning," so the change of cavitation shape will ultimately affect the motion characteristics of the vehicle. In order to study the influence of the bow rudder on the supercavitation, according to the numerical simulation results of the bow rudder model, the supercavity shape is characterized by the iso-surface of the $50 \%$ gas volume fraction.

Considering that both the bow rudder and the rudder angle will have a significant impact on the supercavitation morphology, in order to highlight the focus of this research, only the $0^{\circ}$ rudder angle condition is taken as an example to analyze the influence of the bow rudder on the supercavitation morphology. The shape of the supercavitation, when the bow rudder angle is $0^{\circ}$, is shown in Figure 3 . The overall cavitation morphology is shown in Figure 3(a), and the initial cavitation morphology is shown in Figure 3(b). The numerical simulation results shown in Figure 3 are similar to the supercavity morphological characteristics obtained by the water tunnel test of the star-shaped cavitation in the literature [8].

Figure 3(a) shows that the supercavity generated by the bow rudder model is ellipsoid-like overall, and the maximum cross-sectional diameter of the bubble is in the middle position. The bow rudder cavitation has a great impact on the previous part of the main cavity. Figure 3 (b) shows that four tail cavities are pulled out by the bow rudder, which significantly changes the morphology of the forepart of the supercavity. With the development of the main cavity, the tail cavities gradually merge with the main cavity.

The bow rudder model adopts the "cross-rudder" layout mode, which makes the cavitation profile of the crosssection of the rudder blade different from other section. According to the numerical simulation results, the cavitation axial section contour lines are extracted, and the cavitation contour lines through the axial section of the rudder blade and the axial section between the two rudder blades are, respectively, extracted for the bow rudder model. The two sections are vertical section (section 1 ) and $45^{\circ}$ oblique section (section 2), which are reflected in the axial view of the bow rudder model in Figure 1. The comparison between the different cross-sectional contour lines of the supercavitation of the bow rudder model and the cavitation longitudinal profile of the no bow rudder model is shown in Figure 4.

Figure 4 shows that under the same flow conditions, the geometric dimensions of the supercavitation generated by the bow rudder model are larger than the supercavitation generated by the single cavitation model, in which the axial length is $7.7 \%$ larger. The cavitation profile of section 1 is affected by the bow rudder, and the symmetry of the cavitation bubble is destroyed, and the section with the largest radial dimension moves backward. The radial dimension of section 2 is larger than that of section 1, and the profile of the cavitation is still elliptical. With the development of cavitation, the difference between section 1 and section 2 gradually decreases.

In order to study the influence of the bow rudder on the cavitation development process, according to the numerical simulation results, the cavitation contours of the crosssections at different axial positions with the distances of $0.1 \mathrm{Lm}, 0.3 \mathrm{~L} \mathrm{~m}, 0.5 \mathrm{Lm}$, and $0.7 \mathrm{Lm}$ from the cavitation are extracted and compared. The comparison of the cavitation contour lines corresponding to different axial positions is shown in Figure 5.

Figure 5 shows that the bow rudder has a significant effect on the shape of supercavitation and will change the original circular cross-section of the cavity. The rudder blade changes the position of the cavitation seriously, and the cavitation depression caused by the bow rudder disappears after the middle section.

\subsubsection{The Hydrodynamic Characteristics of the Bow Rudder.} The wetness of the bow rudder is not affected by the supercavitation of the main body; therefore, the rudder effect is stable during the steering process, and the control force is only related to the rudder angle. The hydrodynamic force of the bow rudder includes the resistance in the same direction as the incoming flow and the lift perpendicular to the incoming flow. In order to facilitate the analysis, the hydrodynamics of the bow rudder are dimensionless, and the reference quantities are the incoming flow velocity, the density of water, and the wetted area of the rudder blades (the wetted area of the rudder blades is defined as the area of the longitudinal section of the wetted part). The hydrodynamic characteristics of the bow rudder after the nondimensionalization are shown in Figure 6. 


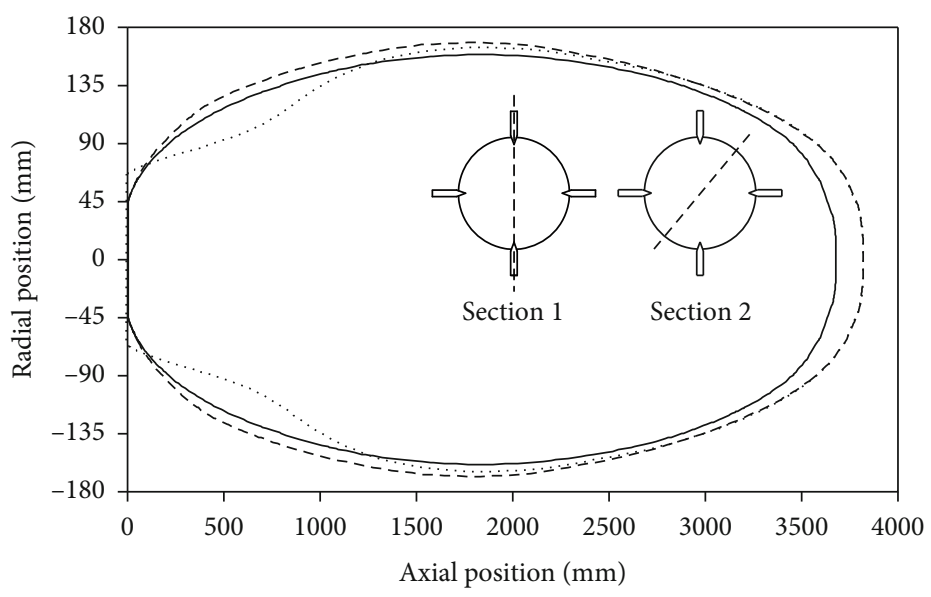

Section 1

- - - Section 2

Cavitator without appendages

Figure 4: Contrast of axial section contour lines of supercavitation of the bow rudder model.

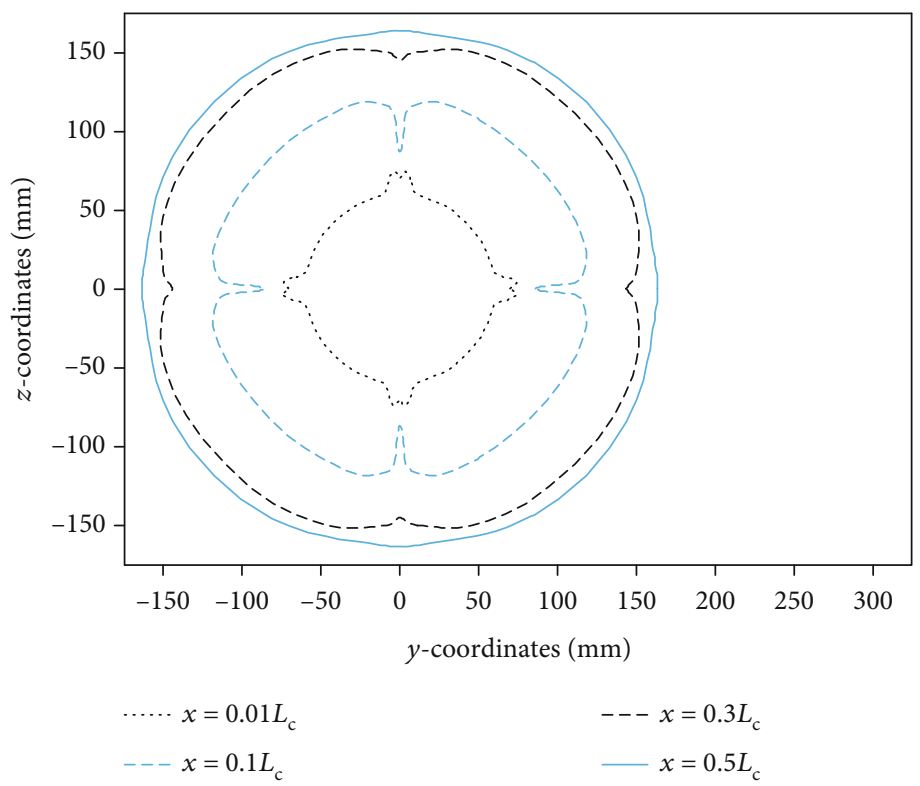

FIgURE 5: Contrast of supercavity transverse section contour lines of the bow rudder model.

Figure 6 shows that the lift coefficient of the bow rudder is positively correlated with the rudder angle. The linearity is good in the range of $0 \sim 10^{\circ}$, and it is nonlinear in the range of $10 \sim 12^{\circ}$, and the lift derivative gradually decreases. With the increase of the rudder angle, the drag coefficient of the bow rudder is almost unchanged within the range of $0 \sim 5^{\circ}$, and it increases significantly in the range of $6 \sim 12^{\circ}$. The drag coefficient of $12^{\circ}$ rudder angle is about $80 \%$ higher than that of $0^{\circ}$ rudder angle. The bow rudder reaches the maximum lift-todrag ratio of 2.4 at $10^{\circ}$ rudder angle.

3.2. Layout of the Stern Rudder Mode. According to the numerical simulation results of the stern rudder model with a rudder angle of $0 \sim 12^{\circ}$, the hydrodynamic characteristics of the stern rudder are counted to obtain the rudder effect characteristics of the stern rudder. Compared with the model excluding the stern rudder, the influence of the stern rudder on the major supercavity shape is obtained, by analyzing the deformation of the supercavity.

\subsubsection{The Influence of Stern Rudder on Supercavitation} Morphology. According to the numerical simulation results, the supercavitation of the stern rudder model and the unattached vehicle model is compared, and the influence of the stern rudder on the main body supercavitation is analyzed. The stern rudder is located at the tail of the cylindrical section of the supercavitation vehicle, and the shape of the main body's cavitation tail is mainly determined by the drainage 


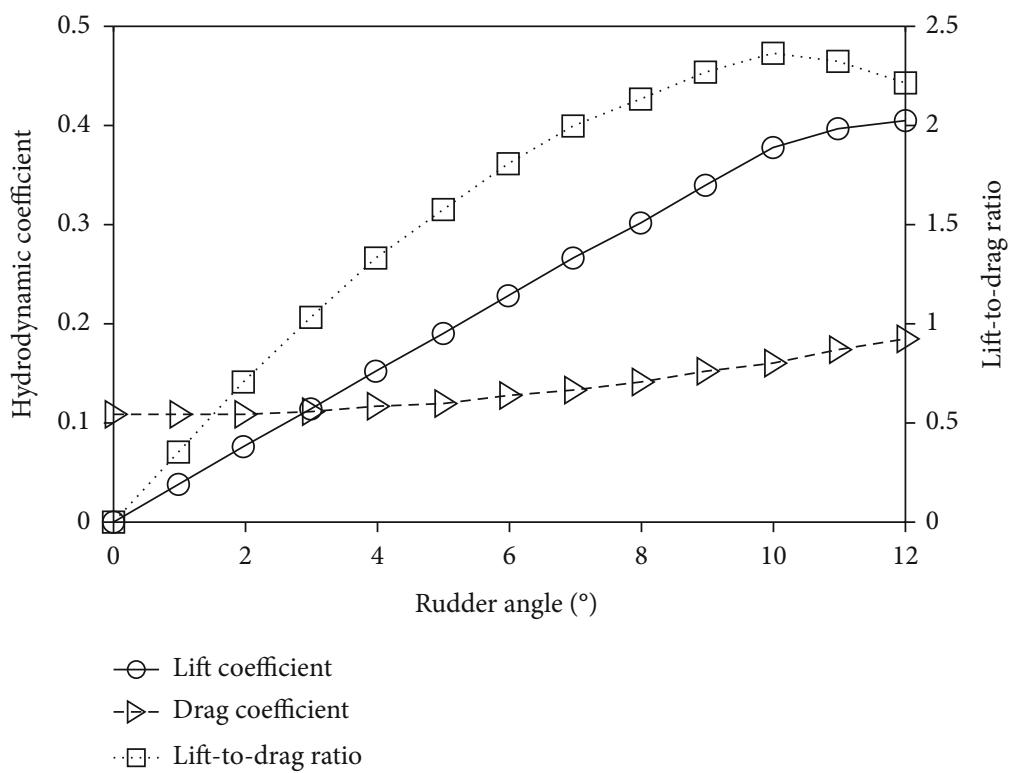

FIGURE 6: The hydrodynamic characteristics of the bow rudder.

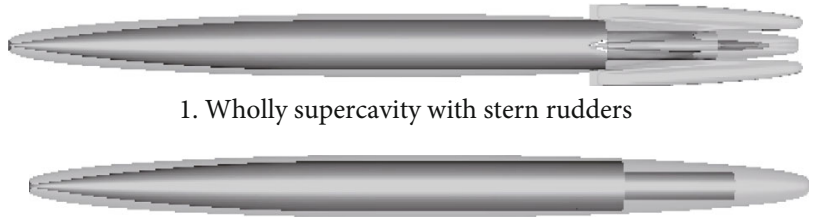

2. Wholly supercavity without stern rudders

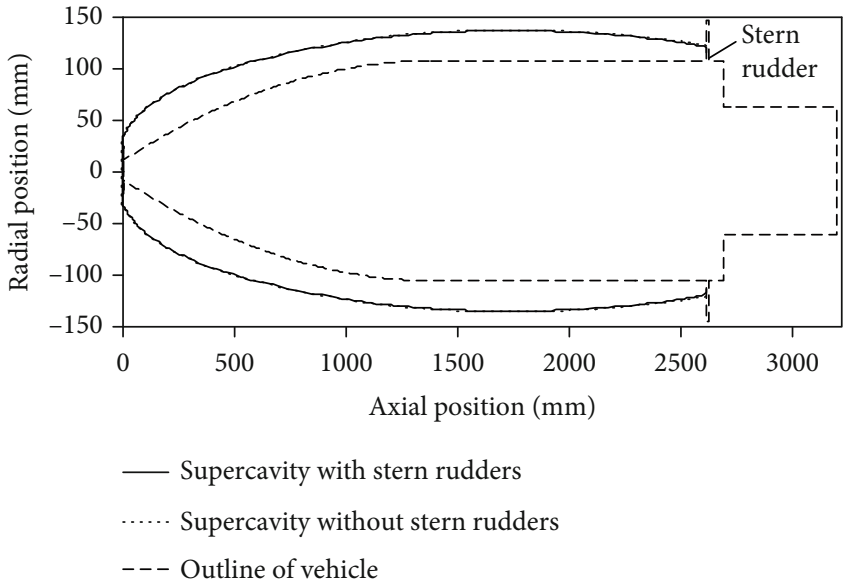

(b) Comparison of supercavity with and without stern rudders

(a) Comparison of supercavity with and without rudders

FIGURE 7: The influence of stern rudder on supercavitation morphology.

of the engine nozzle for actual vehicle. Therefore, the main concern is the influence of the stern rudder on its previous supercavitation morphology. The main cavitation comparison of the stern rudder model and the unattached model is shown in Figure 7(a). The supercavitation contour line obtained by comparing the stern rudder with and without the stern rudder is shown in Figure 7(b).

Figure 7(a) shows that the stern rudder model and the unattached vehicle model have the same shape and size of the supercavitation. Figure 7(b) shows that the supercavitation contour lines obtained from the stern rudder model with and without the stern rudder model almost coincide before the rudder blade, which indicates that the stern rudder does not affect the shape of the supercavitation in front of the rudder.
The stern rudder punctures the main body cavitation, and the high pressure area of the rudder surface causes the cavitation near the rudder blade to dent, which makes the actual wet condition of the stern rudder change significantly. Studying the influence of the stern rudder on the cavitation shape near the rudder blade is helpful to predict the effective wetting area of the rudder blade, and then accurately predict the rudder effect. The comparison between the numerical simulation results and the experimental results of the supercavity deformation of the main body caused by the stern rudder is shown in Figure 8(a). The intersections of cavitation with stern flat rudder and stern straight rudder are shown in Figure 8(b). Figure 8(a) is a water tunnel test result of low-velocity ventilated supercavity. It is different from the numerical simulation conditions and 


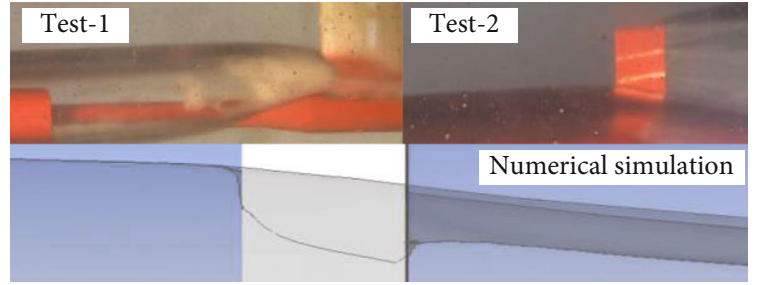

(a) Cavitation depression

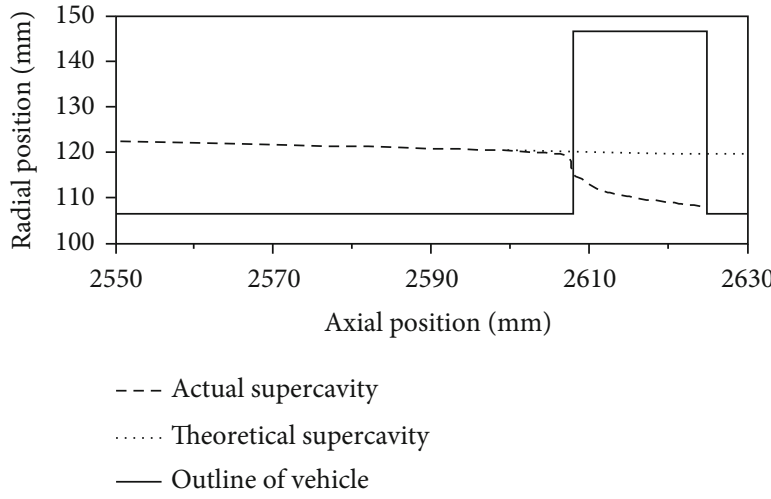

(b) Intersections of cavitation

FIgURE 8: Actual wetting of the rudder under cavitation puncture.

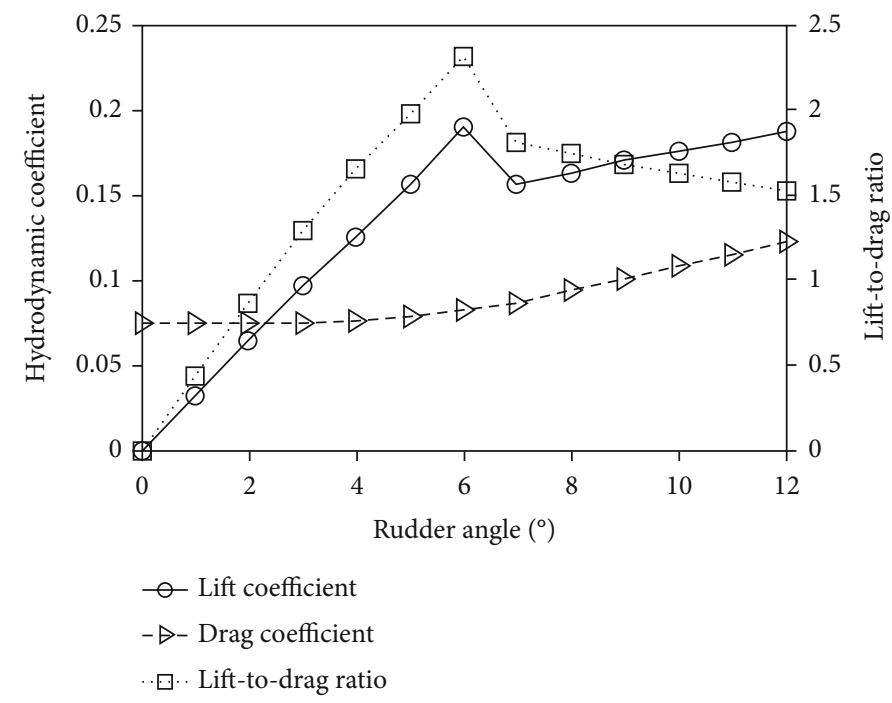

FIGURE 9: The hydrodynamic characteristics of the stern rudder under puncture cavitation.

shows that the stern rudder can cause the cavitation of the main body.

As shown in Figure 8(a), both the numerical simulation and water tunnel test results show that the rudder blade piercing the cavitation will cause supercavity deformation. Figure 8(b) shows that, when the angle of attack of the vehicle and the rudder angle of the stern rudder are both $0^{\circ}$, the actual wetted area of the stern rudder is $800 \mathrm{~mm}^{2}$, which is $246 \mathrm{~mm}^{2}$ larger than the theoretical wetted area. Therefore, the prediction of the rudder efficiency of the stern rudder should consider the supercavity deformation. There is a big difference between the rudder efficiency based on the theoretical cavitation shape and the actual situation.

\subsubsection{The Hydrodynamic Characteristics of the Bow Rudder.} The rudder effect of the stern rudder is directly related to the wetted area of the rudder blade, and the control force is not only related to the rudder angle but also affected by the actual wetted condition of the rudder blade. According to the numerical simulation results, the hydrodynamic force received by the stern rudder is counted, and the rudder effect of the stern rudder under the condition of cavitation puncture is studied. The analysis method of the stern rudder hydrodynamic characteristics and the dimensionless process referred to the bow rudder model are also studied. The hydrodynamic characteristic curve of the stern rudder is shown in Figure 9.

Figure 9 shows the stern rudder lift characteristics show two different stages when supercavitation is punctured. The lift coefficient in the range of $0 \sim 6^{\circ}$ has good linearity with respect to the rudder angle, and the lift coefficient of the rudder blade decreases abruptly at a rudder angle of $7^{\circ}$, even stalling occurs. The lift coefficient is still positively related to the rudder angle within the range of $7 \sim 12^{\circ}$, but it is only equivalent to the lift level at the rudder angle of $5 \sim 6^{\circ}$. The drag coefficient of the stern rudder in the range of $0 \sim 5^{\circ}$ rudder angle does not change much, and it increases significantly with the increase of the rudder angle in the range of $5-12^{\circ}$. 
The drag coefficient of the rudder angle of $12^{\circ}$ increases by $60 \%$ relative to $5^{\circ}$.

\section{Discussions}

Figures 3-5 show the supercavitation generation and development of the bow rudder model, indicating that the bow rudder has a significant influence on the supercavitation morphology. The cross-sectional profile of the bubble is no longer circular, and the symmetry of the bubble is affected. Figures 7 and 8 show the generation and development of supercavitation in the stern rudder model, indicating that the stern rudder has little effect on the main cavitation and does not affect the shape and size of the cavitation in front of the rudder, but only causes local depression of the supercavity near the rudder blade.

Figures 6 and 9 show the hydrodynamic characteristics of the bow rudder model and the stern rudder blade, respectively. The lift coefficient of the bow rudder continues to increase with the increase of the rudder angle in the range of $0-12^{\circ}$. The lift coefficient of the stern rudder increases with the increase of the rudder angle in the range of $0-6^{\circ}$. The lift coefficient of the blade drops suddenly when the rudder angle is $7^{\circ}$. Although the lift coefficient in the range of $7-12^{\circ}$ is positively correlated with the rudder angle, the value is only equivalent to the lift level at $5-6^{\circ}$. The maximum lift coefficient of the bow rudder is 0.41 , while the stern rudder is only 0.19 . Taking the effective wetted area of the rudder blade as a reference value, the lift derivative of the bow rudder is greater than that of the stern rudder. In addition, considering that the distance from the cavitation of the conventional supercavitation vehicle to the center of gravity is about twice the distance from the stern rudder to the center of gravity, therefore, the bow rudder control mode has better maneuverability.

In summary, the bow rudder model has good hydrodynamic characteristics, stable rudder efficiency, and large usable rudder angles. Thus, the bow rudder of the same size can provide greater control force and torque for the aircraft, but it has a greater impact on the cavitation shape, which will affect the prediction accuracy of the hydroplaning of the hull. The influence of the stern rudder model on the previous supercavitation shape of the rudder blade is negligible, but its effective wetting length is affected by the relative position between the vehicle and the supercavitation. In addition, the cavitation near the rudder blade also significantly affects the effective wetting area of the rudder blade, which brings difficulties to the hydrodynamic prediction of the stern rudder.

Based on the above analysis, the advantages and disadvantages of the supercavitating vehicle bow and stern rudder control modes are complementary. Reducing the elongation of the bow rudder reasonably weakens the influence of its multicavitation morphology, and reducing the chord length of the stern rudder can weaken the influence of the main cavitation on the rudder effect. Therefore, a large aspect ratio bow rudder and a small aspect ratio stern rudder are used to implement joint control of the supercavitation vehicle, which can simultaneously take into account the supercavitation shape and control force.

\section{Conclusions}

In this paper, a numerical model is established for the supercavitating vehicle in the bow and rudder control mode, and the numerical simulation is carried out for the $0 \sim 12^{\circ}$ rudder angle. According to the numerical simulation results, the influence law of supercavitation shape and its hydrodynamic characteristics of the bow and stern rudder are studied. The following conclusions can be drawn:

(1) In the bow rudder control mode, the rudder blades have good hydrodynamic characteristics, stable rudder effect, and large available rudder angles, which can provide greater control force and torque. The bow rudder has a greater influence on the supercavity morphology, and the cross-sectional profile of the cavity before the midsection is significantly changed

(2) In the stern rudder control mode, the rudder blade has almost no effect on the cavitation shape in front of the rudder. The wetted length of the rudder blade is determined by the relative position relationship between the aircraft and the cavitation, and the actual rudder effect is related to the attitude and supercavitation morphology of the aircraft. The control force of the stern rudder is difficult to predict accurately

(3) The advantages and disadvantages of the bow rudder control mode and the stern rudder control mode are complementary. The use of a small aspect ratio bow rudder and a large aspect ratio stern rudder to implement joint control of the aircraft can simultaneously take into account the supercavitation shape and control force

The research in this paper can provide a reference for the optimization of the hydrodynamic layout of the supercavitating vehicle and the design of the control model.

\section{Data Availability}

The data used to support the findings of this study are available from the corresponding author upon request.

\section{Conflicts of Interest}

The authors declare that there is no conflict of interest regarding the publication of this paper.

\section{References}

[1] L. Kai, L. Dai-Jin, D. Jian-Jun, W. Yu-Cai, and Z. Yu-Wen, "Motion control model of supercavitating vehicle considering time-delay effect of supercavitation," Journal of Traffic and Transportation Engineering, vol. 10, no. 3, pp. 41-45, 2010.

[2] M. A. Hassouneh, V. Nguyen, B. Balachandran, and E. H. Abed, "Stability analysis and control of supercavitating 
vehicles with advection delay," Journal of Computational and Nonlinear Dynamics, vol. 8, no. 2, p. 21003, 2013.

[3] L. Kai, L. Dai-Jin, Q. Kan, D. Jian-Jun, and W. Yu-Cai, "Hydrodynamic layout of strongly maneuvering underwater supercavitating vehicle," Journal of Traffic and Transportation Engineering, vol. 10, no. 4, pp. 45-57, 2010.

[4] V. Nguyen, Dynamics and Control of Non-smooth Systems with Applications to Supercavitating Vehicles, University of Maryland, College Park, 2011.

[5] J. H. Wang, Y. J. Wei, K. P. Yu, C. Wang, W. H. Huang, and R. Lu, "Modeling and control of underwater supercavitating vehicle based on memory effect of cavity," Zhendong yu Chongii(Journal of Vibration and Shock), vol. 29, no. 8, pp. 160-163, 2010.

[6] D. Li, K. Luo, C. Huang, J. Dang, and Y. Zhang, "Dynamics model and control of high-speed supercavitating vehicles incorporated with time-delay," International Journal of Nonlinear Sciences and Numerical Simulation, vol. 15, no. 3-4, pp. 221-230, 2014.

[7] J. Dzielski and A. Kurdila, "A benchmark control problem for supercavitating vehicles and an initial investigation of solutions," Journal of Vibration and Control, vol. 9, no. 7, pp. 791-804, 2003.

[8] R. Kuklinski, "Experimental studies in the control of cavitating bodies," in AIAA guidance, navigation, and control conference and exhibit, 2006.

[9] J.-L. Reboud, O. Coutier-Delgosha, B. Pouffary, and R. FortesPatella, "Fifth international symposium on cavitation," in Numerical Simulation of Unsteady Cavitating Flows: Some Applications and Open Problems, Osaka, Japan, 2003.

[10] Z. Guang, Y. Kaiping, Z. Jingjun, and L. Zhenwang, "Numerical research on hydrodynamic characteristics of supercavitating vehicle in the turning motion," Chinese Journal of Applied Mechanics, vol. 3, pp. 278-283, 2012.

[11] K.-p. Yu, G. Zhang, J.-j. Zhou, W. Zou, and Z.-w. Li, "Numerical study of the pitching motions of supercavitating vehicles," Journal of Hydrodynamics, vol. 24, no. 6, pp. 951-958, 2012.

[12] A. D. Vasin and E. V. Paryshev, "Immersion of a cylinder in a fluid through a cylindrical free surface," Fluid Dynamics, vol. 36, no. 2, pp. 169-177, 2001. 